\title{
The pathway of concrete improvement via nano-technology
}

\author{
Alvansazyazdi M.*; Rosero José Augusto* \\ *Universidad Central del Ecuador, Facultad de Ingeniería, Ciencias \\ Físicas y Matemática \\ Quito, Ecuador \\ e-mail: faridalvan@uce.edu.ec \\ e-mail: jarosero@uce.edu.ec
}

\section{Resumen}

La nanotecnología es la ciencia que trata la materia en la escala de una billonésima de metro (es decir, $10^{-9} \mathrm{~m}=1 \mathrm{~nm}$ ), y también es el estudio de la manipulación de la materia a escala atómica y molecular. El uso de la nanotecnología puede modificar algunas propiedades del hormigón. En esta revisión, se discute la aplicación de diferentes nanomateriales para mejorar las propiedades convencionales del hormigón. Cada material ultrafino actúa como agente para reducir la formación de microporos, proporcionar una microestructura densa y aumentar las propiedades mecánicas. Así, se recogen las principales tendencias en el uso de nanomateriales destacando las ventajas generadas por la adición de nanopartículas al concreto.

Palabras clave: nanopartículas, $\mathrm{SiO} 2, \mathrm{TiO} 2, \mathrm{Al} 2 \mathrm{O} 3$, Nano clay, CNT.

\begin{abstract}
Nanotechnology is the science that deals with matter at the scale of 1 billionth of a meter (i.e., $10^{-9} \mathrm{~m}=$ $1 \mathrm{~nm}$ ), and is also the study of manipulating matter at the atomic and molecular scale. The use of nanotechnology can modify some properties of concrete. In this review we discuss the application of different nanomaterials to enhance conventional concrete properties. Each ultrafine materials act as agent to reduce formation of micro pores, provide dense microstructure and increase mechanical properties. Thus, the main trends in the use of nanomaterials are highlighted, highlighting the advantages generated by the addition of nanoparticles to concrete
\end{abstract}

Keywords: Nanoparticles, $\mathrm{SiO}_{2}, \mathrm{TiO}_{2}, \mathrm{Al}_{2} \mathrm{O}_{3}$, Nano clay, CNT 


\section{Introduction}

Nanotechnology, which covers synthesis, process, characterization and application of nanomaterials, considerably attracts most attention because of a wide variety of potential and practical application, including medicine, electronics and advanced ceramics. In general, a nanoparticle has an ultrafine size in the range of 1 to $100 \mathrm{~nm}$. The typical properties of nanoparticles are considerably different from those of the bulk materials. In the last decade, nanotechnology was used in different engineering field, especially in the civil engineering. A large number of materials such as, glass, concrete, steel can be improved by the use of nanotechnology. Nanoparticles has also different applications in coatings such as paints to develop self-healing capabilities and corrosion protection of coating. Since these coatings have hydrophobic properties and ward the metal surface off water as well can also protect materials from salt water and acid attack. The most useful application of nanotechnology in fields of civil engineering, is in the concrete production.

Concrete includes of amorphous phase, crystals in different size of nanometer to micrometer, and bound water. It can be improved in numerous ways that one of which is composed with nanoparticles. This research covers the effect of incorporation of nano-size spherical materials (e.g., nano-SiO2, $\mathrm{TiO} 2, \mathrm{CaCO} 3, \mathrm{Al} 2 \mathrm{O} 3$, etc.), nano-tubes or fibers [(carbon nanotube (CNT) and carbon nano-fibers (CNF)] and nano-clay into cementitious materials.

The beneficial effect of the nanoparticles on the performance of cementitious materials can be explained by the different following factors

- Nanoparticles that well-dispersed can act as nuclei for cement phases, hence promoting the hydration due to their high reactivity;

- Use of Nanoparticles lead to crushed size of crystals (such as $\mathrm{Ca}(\mathrm{OH})_{2}$ ) and also formation of small-sized uniform clusters of C-S-H;
- Nanoparticles accelerate the pozzolanic reactions, resulting in the consumption of $\mathrm{Ca}(\mathrm{OH})_{2}$ and formation of an "additional" C-S-H gel;

- structure of the aggregates 'contact zone' can be improved by use of nanoparticles, resulting in a better bond between cement paste and aggregates; and

- Nanoparticles provide crack detention and interlocking effects between the slip planes, which improve the toughness, shear, tensile and flexural strength of cement-based materials.

- Nanoparticles can act as nano reinforcement and strong the tensile strength of concrete.

Most research on nanotechnology in concrete has focused on the use of nanoparticles to investigation of structure and mechanical properties of nano-concrete.

\section{Incorporation of $\mathrm{SiO}_{2}$ nanoparticles}

The mechanical properties of cement mortars can be varied with addition of nano particles. It has been observed that $\mathrm{SiO}_{2}$ nano-particles can be increased compressive and flexural strengths of cement mortars [1,2]. The compressive strengths of cements with nano-silica (NS) were all higher than those of cements containing silica fume at setting time of 7 and 28 days. Results showed $26 \%$ increase of 28 days compressive strength with addition of $10 \%$ nano-SiO2 whereas addition of $15 \%$ silica fume lead to increase of $10 \%$ compressive strength [2]. In other investigation it is found that the addition of small volumes of NS (i.e., $0.25 \%$ ) caused $25 \%$ increase of flexural strength and $10 \%$ increase of compressive strength at 28 days [3].

The mechanisms for increase performance of concrete with nano- $\mathrm{SiO}_{2}$ has been studied at different levels. Uniformed Dispersion of nanoparticles in the cement paste, increased deposition of 
the hydrated products of cement on it due to their great surface energy, i.e., act as nucleation sites. Nucleation of hydration products on nano-particles further improve and accelerates cement hydration [4]. The other mechanisms of improved performance of concrete by addition of nanoparticles are (i) the nano-size pores of the cement paste fill with nanoparticles, and (ii) Nanosilica influence pozzolanic reaction and reacts with $\mathrm{Ca}(\mathrm{OH}) 2$ and generates additional C-S-H [5]. the particle size and the proper dispersion of the nano particles is important factor in effective improvement and the colloidal dispersions being more effective than the powder in cement paste [6]. The addition of Nanosilica provides major improvement of early age of concrete structure respect to crystal orientation degree, reduction in content, and crystal size of portlandite crystals was reported [7] as could be observed at the following Fig. 1 and Fig. 2 under the Scanning Electron Microscopy (SEM).

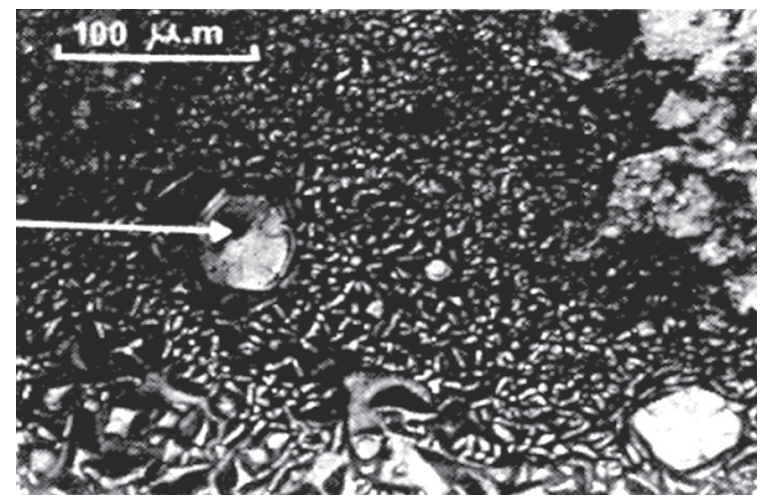

Fig. 1. Particles (indicated by an arrow), surrounded by solid phase portlandite.

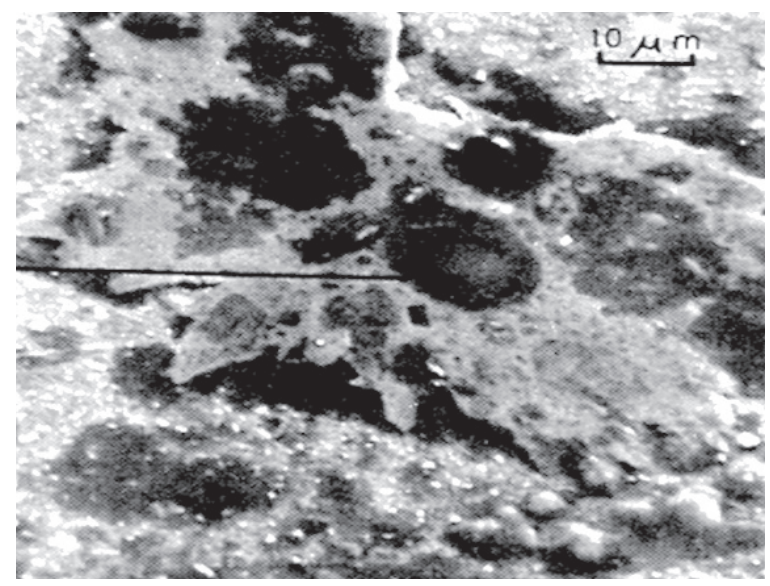

Fig. 2. Particles marked with an arrow in the previous Figure 1with the irregular morphology of the portlandite support.
The addition of $\mathrm{SiO}_{2}$ nanoparticles resulted in the increase of heat of hydration process and chemically combined water percentage and decrease of $\mathrm{CH}$ content [8]. In other research [9], the microstructural studies showed that the increase in strength due to addition of nano- Sio 2 was not related to pozzolanic reaction but due to the growth of silica chains in C-S-H and causing dense microstructure.

The water permeability resistant behavior of nano silica concrete is better than of normal concrete [10].

By addition of nano-silica to Light Weight Concrete resistance to water and chloride ions penetration was enhanced despite strength slightly increased. The resistance against chloride ion penetration, water penetration and sorptivity was improved by addition up to $2 \%$ Nanosilica to concrete [11].

The addition of colloidal nano-silica to concrete (without and with class $\mathrm{F}$ fly ash binder) result in improvement of overall performance of concrete. Adiabatic temperature test within $15 \mathrm{~h}$ after mixing indicate that ultrafine nature of nano-silica was responsible for speeding up the kinetics of hydration reactions. The strength of concrete increased with the addition of nano- $\mathrm{SiO}_{2}$ up to $6 \%$, showed that addition of small dosages of nano-silica can controlled destructive effect of fly ash on strength performance. Also it was showed a decrease in passing charges and physical penetration depths because of reducing the conductivity and dense structure [12].

Nano $\mathrm{SiO}_{2}$ could significantly increase the compressive strength of high volume fly ash and also rice husk concrete. The concretes containing 2 and $4 \%$ of nano silica exhibited similar compressive strength and it is showed effectiveness of high percentage of nanoparticles in HVFA concrete. The durability properties of concretes containing $38 \%$ class F fly ash and $2 \%$ nano-silica as replacement of cement are higher than ordinary concrete [13].

Also addition of Nano-silica to Rice husk Ash (RHA) concrete improving its mechanical properties research showed that blending $1 \%$ Nano- 
silica to 20\% RHA concrete caused an increase in compressive and flexure strength. In general, by addition Nanosilica particles up to $1 \%$ to concrete the disadvantages of rice husk ash had overcome [14].

\section{Incorporation of $\mathrm{TiO} 2$ Nanoparticles}

$\mathrm{TiO}_{2}$ nanoparticles has wide applications due to its high oxidizing capability under near UV-radiation, chemical stability in different environment (both acidic and basic environments), absence of toxicity. Several studies have shown that nano- $\mathrm{TiO}_{2}$ can improve the early-age hydration of cement [15] and increase compressive and flexural strengths [16]. The abrasion resistance of concrete containing different nanoparticles (both nano- $\mathrm{TiO}_{2}$ and nano-SiO${ }_{2}$ ) is experimentally studied [15] and it is found that the abrasion resistance of concrete containing nano$\mathrm{TiO}_{2}$ is higher than Nanosilica and optimum amount of nano $\mathrm{TiO}_{2}$ is $1 \%$ for effectiveness in enhancing abrasion resistance. With the increase of nano $\mathrm{TiO}_{2}$ content up to $5 \%$ the abrasion resistance decreases. Concrete containing nano- $\mathrm{TiO}_{2}$ has self-cleaning properties for de-polluting the environments. Nano- $\mathrm{TiO}_{2}$ act as a photocatalytic agent to degradation of pollutants (e.g., NOx, CO, VOCs, chlorophenols, and aldehydes from vehicle and industrial transpiration) $[17,18$, 19]. A clean $\mathrm{TiO}_{2}$ concrete exposed to sunlight can purificate the harmful NOx gases from the atmosphere by oxidation to nitrates. [20].

In other study, a photocatalytic concrete with nano- $\mathrm{TiO}_{2}$ nanoparticles was fabricated. Results show that the surface of nano concrete was covered by a layer contain C-S-H and $\mathrm{TiO}_{2}$ nano particles around tens of $\mathrm{nm}$ and the roughness of the nano concrete was about 3.5-11 nm. Due to its photocatalytic properties and high-smooth surface, this concrete can used as a material for the urban application [21].

The effect of the addition of $\mathrm{TiO}_{2}$ on the con- crete compaction and mechanical properties was investigated. The results indicated that addition of $\mathrm{TiO}_{2}$ nanoparticles to concrete increase the amount of C-S-H (calcium silicate hydrate), compressive strength at 28 days and a reduction in the modulus of elasticity of the nano concretes. In relation to the percent of concrete porosity, the addition of $\mathrm{TiO}_{2}$ nanoparticles in the both form of $10 \%$ anatase II and rutile resulted in a decrease in the overall pore volume, pore restoration and improve distribution of the pore lengths. $\left\{\right.$ Study of the influence of nano- $\mathrm{TiO}_{2}$ on the properties of Portland cement concrete for application on road surface. Another benefit of $\mathrm{TiO}_{2}$ is increasing abrasion resistance and strength of concrete at early age [22].

In self-compacting concrete containing class F fly ash (5-15\%). It was found that addition of $\mathrm{TiO} 2$ up to $4 \%$ could lead to improvement of detrimental effect of flu ash on flexural strength by accelerate formation of C-S-H gel at the early age of hydration. Also, nano $\mathrm{TiO}_{2}$ nanoparticles lead to increasing in consistency and reducing in the possibility of bleeding and segregation [23].

Marine environment is destructive for concrete structures that create the coupled attack of chloride diffusion and scouring. Concrete containing $1 \%$ nano-TiO2 shows a high scouring abrasion resistance and a low diffusion coefficient. Furthermore nano Tio2 can improve more resistance to chloride diffusion [24].

\section{Incorporation of $\mathrm{CaCO} 3$}

The CaCO3 nanoparticles is very useful in cement alternative. In recent developments in concrete technology ultra-high-performance concrete (UHPC) is produced that are characterized by very low water-to-cement (w/c) ratios. Hence, high amount of the cement in concrete will not hydrate and will just act as filler. Therefore, use of non-costly filler material to replacing cement are interest. In research showed that addition of micro-CaCO3 
to concrete acted as a filler, improvement of microstructure and increasing the effective $\mathrm{w} / \mathrm{c}$ ratio [25] but nano- $\mathrm{CaCO} 3$ act as accelerator of the early-age hydration process, and an effective filler to concrete. The combining of both micro- and nano- $\mathrm{CaCO} 3$ resulted in better performance not only for enhancing of mechanical properties but also to replacement of cement up to $20 \%$ [26].

In other research results showed that nano-CaCO3 slurry increase the mechanical strength of the concrete with and without fly ash at the early ages. Actually, nano- $\mathrm{CaCO}_{3}$ modified the strength and microstructure of concrete containing fly ash by accelerate both the hydration of cement at early ages and the hydration of fly ash at late ages [27]. Also in the research of nanoparticles addition to different grade of concrete (C30 and C50) it was found that in the low strength grade of concrete adding nano- $\mathrm{CaCO}_{3}$ created calcium carbon-aluminum hydrate with lower carbon that can promote the strength of concrete at early age. But, in the high strength grade of concrete, these improvement disappeared [28].

Compared between addition of chloride- and non-chloride based accelerating admixtures and nano-calcium carbonate $\left(\mathrm{CaCO}_{3}\right)$ at rates of 0 , $2.5,5,10$ and $15 \%$ on properties of ultra-high performance concrete showed that concrete containing nano- $\mathrm{CaCO}_{3}$ had better effect on accelerating of hydration and compressive strength on early-age setting, improved the flowability of mixture and increase workability of concrete and also reducing the risk of steel corrosion induced by chloride-based accelerating admixtures. Consideration of the performance and economic approach determined that addition $5 \%$ up to $10 \%$ nano- $\mathrm{CaCO}_{3}$ to UHPC concrete can cause better improvement for concrete properties [29].

Conduction calorimeter based test results [30] showed that the addition of nano- $\mathrm{CaCO}_{3}$ considerably accelerated the speed of heat progress and shortened the induction period of $\mathrm{C}_{3} \mathrm{~S}$ hydration. It was proposed that nano- $\mathrm{CaCO}_{3}$ can shorten the induction period of $\mathrm{C}_{3} \mathrm{~S}$ hydration by broke down the protective layer of it or accelerated the $\mathrm{C}-\mathrm{S}-\mathrm{H}$ nucleation (i.e., seeding effect) in the paste solution of high ionic concentration.

\section{Incorporation of Nano- $\mathrm{Al} 2 \mathrm{O} 3$}

There are few studies on the use of nano alumina in concrete. Nano- $\mathrm{Al}_{2} \mathrm{O}_{3}$ particles was very effective to increase the modulus of elasticity of cement. With the addition 5\% nano- $\mathrm{Al} 2 \mathrm{O} 3$ to concrete, the elastic modulus increased by $143 \%$ at 28 days whereas compressive strength was not very obvious changed [31]. Frost resistance property of concrete can be significantly increased by the addition of nano-Al2O3 and nano-SiO2. These nano-materials behave as accelerators of pozzolanic reaction and also improve the pore structure of concrete and densifying the microstructure. It is found that the frost resistance of nano- $\mathrm{Al}_{2} \mathrm{O}_{3}$ particles is better than the same amount of nano-SiO2 particles [32]. Also it is found that replacement of cement by $\mathrm{Al}_{2} \mathrm{O}_{3}$ nanoparticles up to $1 \%$ proportional increase flexural strength and Split Tensile strength of cement mortar [33].

Dispersion of cement in UHPC must take place simultaneously with silica action in the hydration of cement because of high proportion of cement in this concrete. Without nano alumina, the hydration process will be slower because silica component cannot penetrated to the internal structure of hydration gel. Nano alumina created the path of injection silica or binding materials into the microstructure of hydration gel and the refining activity will start $[34,35,36]$.

\section{Incorporation of nano clay}

Nano clays depending on the chemical composition and nanoparticle morphology, have several classes such as montmorillonite, bentonite, kaolinite, hectorite, and halloysite. Nanoclay particles enhanced the mechanical properties, the self-compacting properties of concrete and reduce the ability of chloride penetration, permeability and shrinkage [37,38,39]. Montmorillonite clay has unique structure that make it an excellent base for manipulation through nanotechnology. 
Montmorillonite clay has different properties such as stability, an interlayer space, high hydration and swelling capacity and a high chemical reactivity. Organo-modified montmorillonites (OMMT) are employed as fillers and reinforcements in concrete. [38]. The use of low percentage of Nanoclay particles can effectively influence the freshstate properties of concrete.

Nanoclay particles can provide high viscosity by increasing the adhesion between the ingredients of the fresh mixture. Incorporation of small dosages nano-montmorillonite (NMMT) clays (.25, $.50, .75$ and $1.00 \%$ ) to self-compacting concrete (SCC) was investigated. It was found that the addition of .5\% and .75\% NMMT increase compressive strength and splitting tensile strength, respectively. Also, the addition of NMMT clays up to $1.00 \%$ improved durability and electrical resistivity of specimens [40].

\section{Incorporation of CNT}

In Concrete containing fibers (typically steel or polypropylene fibers) control of plastic shrinkage cracking and drying shrinkage cracking increased. The addition of fibers to mix concrete lower the permeability of the fiber reinforce concrete and promote the impact, abrasion and shatter resistance. The important properties of fibers in FRC include diameter, specific gravity, high Young's modulus and tensile strength $[41,42]$.

In recent years, researchers have explored the option of using CNTs as fibers in concrete.

Carbon nanotubes are a form of carbon with cylindrical shape, and diameter size in nanometer scale. Nanotubes have the fullerene structure. single-walled nanotube (SWNT) and multiwalled nanotube (MWNT) are two categories of nanotubes [43].

Carbon nanotubes/nanofibers (CNTs/CNFs) have nano-reinforcements application in cement-based materials. CNTs/CNFs exhibit extraordinary strength with elasticity module of $\mathrm{CNTs} / \mathrm{CNF}$ is in the range of TPa and tensile strength in the order of $\mathrm{GPa}$, with unique electronic and amazing chemical properties [44,
$45,46]$. Concrete has poor tensile strength with prone to brittle and crack. One of the methods to increase tensile strength, ductility and improve durability is the incorporation of fibers into concrete. The mixture of carbon nanotubes and cement hydrates provides high strength properties. Carbon nanotubes can act as bridges across cracks and pores, which load transfer across cracks and pores [47].

Addition of small dosage (e.g., $0.025 \%$ by weight of cement) of homogeneously dispersed multiwall carbon nanotubes (MWCNTs) increase significantly the flexural strength and stiffness of concrete. It is found that adding small amount of carbon nanotube ( $1 \%$ wt.) improve both compressive and flexural strength. Also results show that addition of CNT increases the compressive strength up to $70 \%$ and decreases the heat conductivity up to $12 \%$ in fiber reinforce concrete[48]. One of the important benefits of used of the CNT instead of steel fiber to reinforcement of concrete is that CNTs will not corrode in corrosive environments. This benefit may provide application of CNT in marine environments.

\section{Conclusions}

In practice, under the Scanning Electron Microscopy (SEM) it is possible to observe with certainty how working at nanodimensions opens an enormous potential for the improvement of concrete.

The different uses of nanoparticles not only reveal the capacity of the nanomaterials considered in this review, but also point the way forward for Concrete Improvement Via Nano-Technology.

The applications of the nanomaterials that have been presented also indicate the possibility to lower costs in the use of improved concrete. Each incorporation raises different answers whose experimental characteristics open keys to an increasingly interesting and more investigative world. 


\section{References}

[1]-Li, G.: Properties of high-volume fly ash concrete incorporating nano-SiO2. Cement and Concrete Research 34, 10431049 (2004)

[2]-Li, H., Xiao, H.-g., Yuan, J., Ou, J.: Microstructure of cement mortar with nano-particles. Compos. B Eng. 35(2), 185-189 (2004)

[3]-Sobolev, K., Flores, I., Torres-Martinez, L.M., Valdez, P.L., Zarazua, E., Cuellar, E.L.: Engineering of $\mathrm{SiO} 2$ nanoparticles for optimal performance in nano cement-based materials. In: Bittnar, Z., Bartos, P.J.M., Nemecek, J., Smilauer, V., Zeman, J. (eds.) Nanotechnology in construction: Proceedings of the NICOM3, 3rd International Symposium on Nanotechnology in Construction, Prague, Czech Republic, pp. 139-148 (2009)

[4]-Bjornstrom, J., Martinelli, A., Matic, A., Borjesson, L., Panas, I.: Accelerating effects of colloidal nanosilica for beneficial calcium-silicate-hydrate formation in cement. Chem. Phys. Lett. 392(1-3), 242-248 (2004).

[5]-Jo, B.-W., Kim, C.-H., Lim, J.-H.: Characteristics of cement mortar with nano-SiO2 particles. ACI Materials Journal 104(4), 404-407 (2007)

[6]-Gaitero, J.J., Campillo, I., Mondal, P., Shah, S.P.: Small Changes Can Make a Great Differences. Journal of Transportation Research Record 1(2141), 1-5 (2010).

[7]-Qing, Y., Zenan, Z., Deyu, K., Rongshen, C.: Influence of nano-SiO2 addition on properties of hardened cement paste as compared with silica fume. Construct Build Mater 21(3), 539-545 (2007).

[8]-Lu, Z.-y., Xu, X.: Effect of nanometer $\mathrm{SiO} 2$ on hydration character of portland cement. Jianzhu Cailiao Xuebao 9(5), 581-585 (2006) (in Chinese).
[9]-Dolado, J.S., Campillo, I., Erkizia, E., de Miguel, Y.R., de Ibarra, Y.S., Porro, A., Ayuela, A.: Effects of Nanosilica Additions on Cement Pastes. Applications of Nanotechnology in Concrete Design. In: Proceedings of the International Conference Applications of Nanotechnology in Concrete Design, pp. 87-96 (2005).

[10]- Ji, T.: Preliminary study on the water permeability and microstructure of concrete incorporating nano-SiO2. Cement Concr. Res. 35(10), 1943-1947 (2005).

[11]- HongjianDu, SuhuanDu, XuemeiLiu, Effect of nano-silica on the mechanical and transport properties of lightweight concrete, Construction and Building Materials, Volume 82, 1 May 2015, Pages 114-122.

[12]-A.M.Said, M.S.Zeidan, M.T.Bassuoni, Y.Tian, Properties of concrete incorporating nano-silica, Construction and Building Materials, Volume 36, November 2012, Pages 838-844.

[13]- S.W.M. Supit , F.U.A.Shaikh , "Durability Properties of High Volume Fly Ash Concrete Containing Nano-Silica”, Materials and Structures, 2014.

[14] - K.V.Priya, D.Vinutha, "Effect of Nano Silica In Rice Husk Ash Concrete." India IOSR Journal of Mechanical and Civil Engineering, PP. 39-43, 2014.

[15]-Jayapalan, A.R., Lee, B.Y., Fredrich, S.M., Kurtis, K.E.: Influence of additions of anatase $\mathrm{TiO} 2$ nanoparticles on early age properties of cement-based materials. Journal of Transportation Research Record 1(2141), 41-46 (2010). 
[16]-Li, H., Zhangh, M.-H., Ou, J.-P.: Flexural fatigue performance of concrete containing nanoparticles for pavement. International Journal of Fatigue 29(7), 1292-1301 (2007).

[17]-Vallee, F., Ruot, B., Bonafous, L., Guillot, L., Pimpinelli, N., Cassar, L., Strini, A., Mapelli, E., Schiavi, L., Gobin, C., Andre, H., Moussiopoulos, N., Papadopoulos, A., Bartzis, J., Maggos, T., McIntyre, R., Lehaut-Burnouf, C., Henrichsen, A., Laugesen, P., Amadelli, R., Kotzias, D., Pichat, P.: Cementitious materials for self-cleaning and depolluting facade surfaces. In: RILEM Proceedings (2005), PRO 41 RILEM International Symposium on Environment-Conscious Materials and Systems for Sustainable Development, pp. 337-346 (2004).

[18]-Murata, Y., Obara, T., Takeuchi, K.: Air purifying pavement: development of photocatalytic concrete blocks. J. Adv. Oxidat. Technol. 4(2), 227-230 (1999)

[19]-Chen, J., Poon, C.-S.: Photocatalytic construction and building materials: From fundamentals to applications. Build Environ. 44(9), 1899-1906 (2009)

[20]-Kamitani, K., Murata, Y., Tawara, H., Takeuchi, K.: Air purifying pavement: development of photocatalytic concrete blocks. In: Wu, Z. (ed.) International Symposium on Cement and Concrete, pp. 751-755. International Academic Publishers, Beijing (1998)
[21]-Weiguo Shen, Preparation of $\mathrm{TiO} 2$ nano particle modified photocatalytic self-cleaning concrete, Journal of Cleaner Production, 2014.

[22]- F. Pacheco-Torgal, S. Jalali, Nanotechnology: advantages and drawbacks in the field of construction and building materials, Constr. Build. Mater. 25 (2) (2011) 582-590.

[23]- Mostafa Jalal, Mostafa Tahmasebi, Assessment of nano- $\mathrm{TiO}_{2}$ and class $\mathrm{F}$ fly ash effects on flexural fracture and microstructure of binary blended concrete, Science and Engineering of Composite Materials, Volume 22, May 2015.

[24]-Hui Li, Huigang Xiao, Xinchun Guan, Zetao Wang, Lei Yu, Chloride diffusion in concrete containing nano- $\mathrm{TiO}_{2}$ under coupled effect of scouring, Composites Part B: Engineering, Volume 56, January 2014, Pages 698-704

[25]- Granger S, Loukili A, Pijaudier-Cabot G, Chanvillard G (2005) Mechanical characterization of self-healing effect of cracks in Ultra High Performance Concrete (UHPC) In: Proceedings of 3rd international conference on construction materials, performance, innovations and structural implications, Vancouver, August 22-24.

[26]- J. Camiletti, A. M. Soliman, M. L. Nehdi, Effects of nano- and micro-limestone addition on early-age properties of ultra-high-performance concrete, Mate- 
rials and Structures, Volume 46 , June 2013, pp. 881-898.

[27]-Tao Meng, Yue Yu, Zhongjia Wang, Effect of nano- $\mathrm{CaCO}_{3}$ slurry on the mechanical properties and micro-structure of concrete with and without fly ash, Composites Part B: Engineering, Volume 117, 15 May 2017, Pages 124-129.

[28]-Miao Zhou Huang, Tao Meng, Xiao Qian Qian, Jin Jian Zhang, Influence of $\mathrm{Nano}-\mathrm{SiO}_{2}$ and Nano- $\mathrm{CaCO}_{3}$ on the Mechanical Properties of Concrete with Different Strength Grades, Advanced Building Materials, May 2011, pp. 480484.

[29]-Jessica Camiletti, Ahmed M. Soliman, Moncef L. Nehdi, Effect of nano-calcium carbonate on early-age properties of ultra-high-performance concrete , Magazine of Concrete Research, Volume 65 Issue 5, March 2013, pp. 297-307.

[30]-Sato, T., Diallo, F.: Seeding effect of nano-CaCO3 on the hydration of tricalcium silicate. Journal of Transportation Research Record 1(2141), 61-67 (2010)

[31]-Li, Z., Wang, H., He, S., Lu, Y., Wang, M.: Investigations on the preparation and mechanical properties of the nano-alumina reinforced cement composite. Materials Letters 60, 356-359 (2006).

[32]-Kiachehr Behfarnia, Niloofar Salemi, The effects of nano-silica and nano-alumina on frost resistance of normal concrete, Construction and Building Materials, Volume 48, November 2013, Pages 580-584.

[33]- A. Nazari, Sh. Riahi, Sh.Riahi, S.F.
Shamekhi, A.Khademno, "Mechanical properties of cement mortar with $\mathrm{Al}_{2} \mathrm{O}_{3}$ nanoparticles", Journal of American Science, 2009.

[34]- L. Hui et al., Microstructure of cement mortar with nano-particles, Compos. Part B: Eng. 35 (2) (2004) 185-189

[35]- J. Rosenqvist, Surface Chemistry of Al and Si (Hydr)Oxides, With Emphasis on Nano-Sized Gibbsite (A- $\mathrm{Al}(\mathrm{OH}) 3)$, Department of Chemistry, Inorganic Chemistry, Umeå University, Umeå, Sweden, 2002.

[36]- I.G. Richardson, The nature of C-S-H in hardened cements, Cement and Concrete Research, Volume 29, (1999), pp. 1131-1147.

[37]- Chang, T.-P., Shih, J.-Y., Yang, K.-M., Hsiao, T.-C.: Material properties of portland cement paste with nano-montmorillonite. Journal of Materials Science 42(17), 7478-7487 (2007).

[38]- Kuo, W.-Y., Huang, J.-S., Lin, C.-H.: Effects of organo-modified montmorillonite on strengths and permeability of cement mortars. Cement Concr. Res. 36(5), 886-895 (2006)

[39]- Morsy, M.S., Aglan, H.A., Abd El Razek, M.M.: Nanostructured zonolite-cementitious surface compounds for thermal insulation. Construct Build. Mater. 23(1), 515-521 (2009).

[40]- Payam Hosseini; Alireza Afshar; Bijan Vafaei; Abbas Booshehrian; Elias Molaei Raisi; Amin Esrafili, Effects of nano-clay particles on the short-term properties of self-compacting concrete, European Journal of Environmental and Civil Engineering, Volume 21, 2015, pp. 127-147.

[41]- Brown, R., Shukla, A., Natarajan, K.R.: Fiber reinforcement of concrete structures. URITC Project 536101, University 
of Rhode Island Transportation Center, Kingston, RI, USA (2002)

[42]- Shah, S.P.: Next Horizon in High Performance Concrete: Self-Consolidating Concrete and Nanotechnology. Nanotecnología en el Hormigón Y Hormigones Autocompactantes. Jornada Técnica JT01, 131-151 (2009).

[43]- F.C. Lai, M.F.M. Zain, M. Jamil, Nano cement additives (NCA) development for OPC strength enhancer and Carbon Neutral cement production, in: 35thConference on Our World in Concrete \& Structures, August 2010.

[44]- Ajayan, P.M.: Nanotubes from carbon. Chem. Rev. 99, 1787-1799 (1999)

[45]- Salvetat, J.-P., Bonard, J.-M., Thomson, N.H., Kulik, A.J., Forro, L., Benoit, W.,
Zuppiroli, L.: Mechanical properties of carbon nanotubes. Appl. Phys. Mater. Sci. Process 69, 255-260 (1999)

[46]- Srivastava, D., Wei, C., Cho, K.: Nanomechanics of carbon nanotubes and composites. Appl. Mech. Rev. 56, 215 -

230 (2003)

[47]- Li, G.Y., Wang, P.M., Zhao, X.: Mechanical behavior and microstructure of cement composites incorporating surface-treated multi-walled carbon nanotubes. Carbon. 43(6), 1239-1245 (2005).

[48]- Yakovlev, G., Kerienè, J., Gailius, A., Girniene, I.: Cement based foam concrete reinforced by carbon nanotubes. Materials Science (Medžiagotyra) 12(2) (2006). 